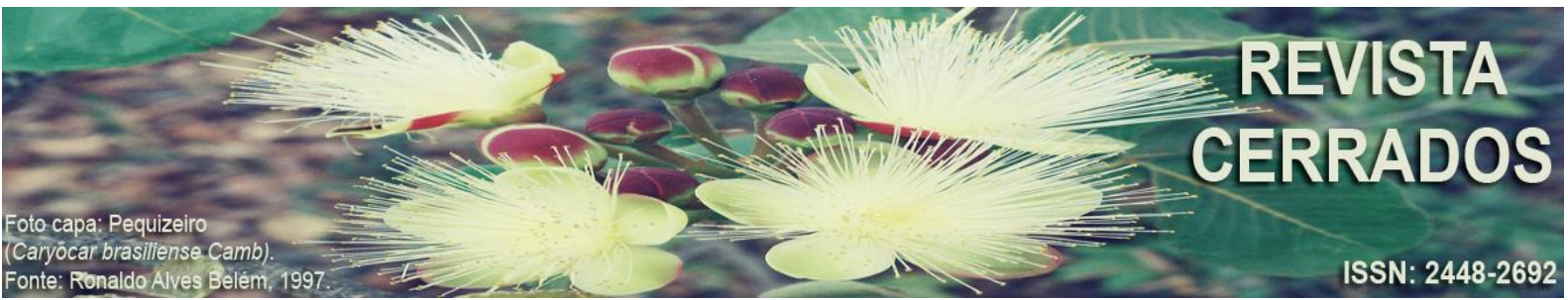

\title{
UTILIZAÇÃO DE ATRIBUTOS TOPOGRÁFICOS NO MAPEAMENTO DE SUSCETIBILIDADE EROSIVA NA ÁREA RURAL DO MUNICÍPIO DE PARANAVAÍ - PR
}

\author{
USE OF TOPOGRAPHIC ATTRIBUTES IN THE EROSIVE \\ SUSCEPTIBILITY MAPPING IN THE RURAL AREA OF THE \\ MUNICIPALITY OF PARANAVAÍ - PR
}

\section{UTILIZACIÓN DE ATRIBUTOS TOPOGRÁFICOS EN EL MAPEO DE SUSCEPTIBILIDAD EROSIVA EN EL ÁREA RURAL DEL MUNICIPIO DE PARANAVAÍ - PR}

José Guilherme de Oliveira Universidade Federal do Paraná - UFPR E-mail: <joseguilhermegeo@gmail.com>.

\author{
Alexei Nowatzki \\ Universidade Federal do Paraná - UFPR \\ E-mail: <nowatzki.a@gmail.com>. \\ Leonardo José Cordeiro Santos \\ Universidade Federal do Paraná - UFPR \\ E-mail: 〈santos@ufpr.br>.
}

\section{Resumo}

A região noroeste do estado do Paraná ao longo dos últimos 50 anos vem sofrendo diversos impactos decorrentes de processos erosivos lineares, ravinas e voçorocas principalmente. A ocorrência desses processos está associada a dois fatores: o histórico de ocupação da região, bem como as características pedológicas locais, principalmente a textura dos solos e sua distribuição nas vertentes. O método adotado para o mapeamento de suscetibilidade é uma adaptação do proposto por Crepani et al. (2001). Esse autor define que a suscetibilidade de uma área é definida pela soma das vulnerabilidades dos componentes do meio físico. Para a realização do trabalho foram selecionados os atributos topográficos declividade e perfil de curvatura; na pedologia, as tipologias de solo. Os resultados foram discretizados em 5 classes: Muito baixa, baixa, média, alta e muito alta suscetibilidade. As áreas de suscetibilidade a erosão Alta e Muito alta, representam $24 \%$ do município, sendo que nessas porções se concentram $26 \%$ das erosões, o tipo de solo em conjunto com as características topográficas 
OLIVEIRA, J. G.; NOWATZKI, A.; SANTOS, L. J. C.

Utilização de atributos topográficos no mapeamento de suscetibilidade erosiva na área rural do município de Paranavaí - PR

fazem essa área mais propicia naturalmente a ocorrência dos processos erosivos. A classe de moderada suscetibilidade a erosão representam cerca de $40 \%$ do município e $54 \%$ das feições erosivas se concentra nessa unidade.

Palavras-chave: Erosão; Modelo Digital de Terreno; Álgebra de Mapas.

\begin{abstract}
The northwest region of the state of Paraná over the last 50 years has suffered several impacts and consequences of linear erosives, ravines and gullies mainly. The occurrence of these processes is mainly associated with two factors: the occupation history of the region, as well as local soil characteristics, mainly the soil texture and a distribution of soils along the slopes. The methodology adopted for the mapping of susceptibility to erosion follows a line of thought developed by Crepani et al. (2001). This proposal defines that the vulnerability of an area is defined by the sum of the vulnerabilities of the components of the physical environment. For the accomplishment of the methodology were selected, to represent the geomorphology, the topographic attributes: slope, curvature plane and profile; for pedology, soil typologies were selected. The results were discretized in 5 classes, from environments less susceptible to the most susceptible. The areas of susceptibility to erosion High and Very high, summed represent $24 \%$ of the municipality, being that in these portions it concentrates $26 \%$ of the area of the erosions, once in these areas the type of soil together with the topographic characteristics make it more propitious to the occurrence of linear erosive processes.The moderate susceptibility to erosion class represent about $40 \%$ of the municipality and $54 \%$ of the area of erosive features is concentrated in this unit.
\end{abstract}

Keywords: Erosions; Digital Terrain Model; Map Algebra.

\title{
Resumen
}

La región noroeste del estado de Paraná en los últimos 50 años viene sufriendo impactos producto de procesos erosivos lineales, regueros y cárcavas principalmente. La ocurrencia de estos procesos está asociada a dos factores: el modo de ocupación de la región y las características pedológicas locales, principalmente la textura de los suelos y su distribución en las vertientes. El método adoptado para el mapeo de susceptibilidad es una adaptación del propuesto por Crepani et al. (2001). Este autor especifica que la susceptibilidad de un área está definida por la suma de las vulnerabilidades de los componentes del medio físico. Para realizar este trabajo fueron seleccionados los atributos topográficos declividad y perfil de curvatura; en la pedología, las tipologías de suelo. Los resultados fueron representados en 5 clases: muy baja, baja, media, alta y muy alta susceptibilidad. Las áreas de susceptibilidad a erosión alta y muy alta, representan el $24 \%$ del municipio, sumado a ello en esas porciones se concentran el $26 \%$ de las erosiones, por lo tanto el tipo de suelo en conjunto con las características topográficas hacen de esas áreas las más propicias naturalmente a la ocurrencia de procesos erosivos. La clase de moderada susceptibilidad a erosión representa cerca del $40 \%$ del municipio y el $54 \%$ de los rasgos erosivos se concentran en esa unidad.

Palabras claves: Erosión; Modelo Digital del Terreno; Álgebra del Mapas. 
INTRODUÇÃO

O recurso solo é de grande importância para o desenvolvimento humano, as primeiras civilizações que se desenvolveram e obtiveram progresso alocavam suas moradias em áreas próximas a grandes rios, localização geográfica definida não só pela disponibilidade hídrica, mas também pela fertilidade das terras ao entorno. Porém, o solo, quando em desequilíbrio com o ambiente, pode passar por diversos processos que causam sua degradação. Dentre esses processos, estão a erosão, a lixiviação, a acidificação e a salinização (LEPSCH, 2010).

Segundo a FAO (2015), cerca de $33 \%$ dos solos aráveis do mundo estão degradados. Ainda segundo o mesmo relatório, as principais causas dessa degradação estão relacionadas aos processos erosivos, em especial os causados pela ação da água.

Na região noroeste do estado do Paraná, os solos possuem basicamente textura arenosa, que resultam em erosões hídricas laminares (que afetam as camadas superficiais dos solos) e lineares (nas formas de sulcos, ravinas e voçorocas). Esses processos, por sua vez, geram consequências sociais e econômicas à população envolvida (SUCEAM, 1994 apud WESTPHALEN, 2008).

Partindo desse contexto, a área de estudo abordada nas discussões do trabalho é o município de Paranavaí, localizado na região noroeste do estado do Paraná, à margem norte do Rio Ivaí (Figura 1). A seleção da área para estudo foi feita a partir das bases cartográficas disponíveis, sendo que o município possui o mapa de solos em escala 1:50.000 (FASOLO et al. 1988). Outro critério utilizado para a seleção da área de estudo foi o trabalho realizado por Mangueira (2014), sendo que nesse trabalho a autora encontrou 46 feições erosivas para o município de Paranavaí.

Do ponto de vista geológico, o município se localiza principalmente na área de ocorrência das rochas do grupo Caiuá, com idade mesozoica e origem sedimentar (Fernandes et al. 2012). Encontra-se situado na unidade morfoescultural do terceiro planalto paranaense, sub-unidade planalto de Paranavaí, caracterizado pela baixa dissecação do relevo e topos aplainados (SANTOS, 2006). Quanto à altimetria, o município tem variação de $230 \mathrm{~m}$ a 550m.

Segundo a classificação climática de Köppen, Paranavaí se localiza no clima Cfa (clima temperado úmido com verão quente), com temperaturas médias anuais entre 22 e $24^{\circ} \mathrm{C}$ e a precipitação anual média fica entre 1200 e 1400mm, nas porções mais ao norte do município, e entre 1400 e 1600mm, nas partes centrais e sul (IAPAR, 1994). 
Figura 1 - Mapa de localização do município de Paranavaí

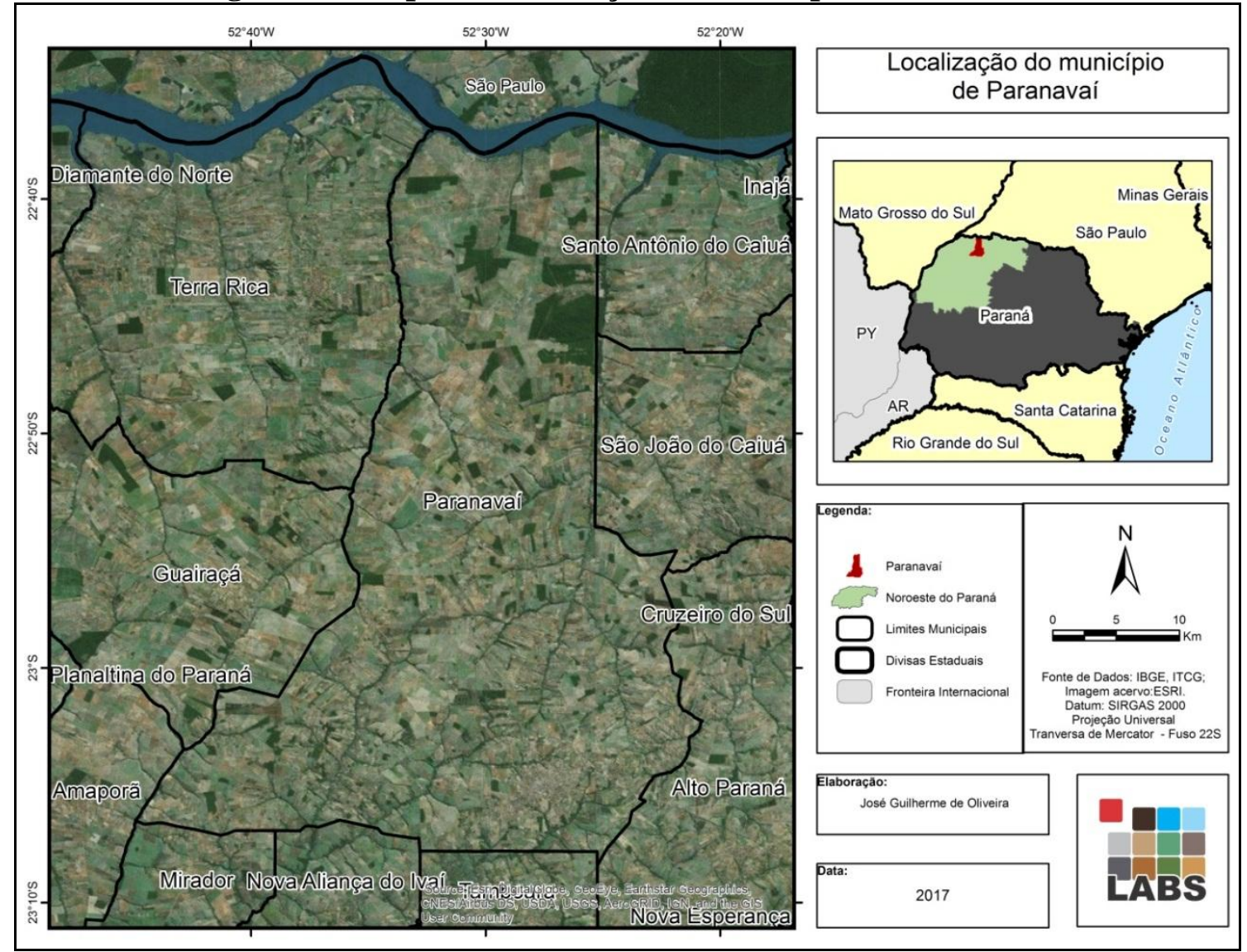

Org. O autor (2017).

As características do meio físico, bem como os processos de ocupação da no noroeste do estado do Paraná, caracterizam a região como de alta ocorrência de problemas relacionados à erosão hídrica (WESTPHALEN 2008).

A proposta do presente trabalho se baseia na premissa de que na região noroeste do estado do Paraná as erosões lineares hídricas afetam tanto as atividades urbanas quantos as rurais (MANGUEIRA, 2017), portanto, um levantamento de áreas que são naturalmente suscetíveis a esses processos pode surgir como uma ferramenta em ações que visem à conservação dos solos.

Existem diversos trabalhos em que as relações do meio físico são preditas através da integração de variáveis geomorfológicas, criando produtos sobre a fragilidade/vulnerabilidade ambiental. (SPORL, 2006; SANTOS E SOBREIRA, 2008; MESQUITA et al. 2010; RIBEIRO E CAMPOS, 2007; WROBLEWSKI E PAULA, 2015).

Logo, o objetivo do presente trabalho foi produzir uma carta de suscetibilidade a erosões, adaptando o método proposto por Crepani (2001), para o município de Paranavaí - 
OLIVEIRA, J. G.; NOWATZKI, A.; SANTOS, L. J. C.

Utilização de atributos topográficos no mapeamento de suscetibilidade erosiva na área rural do município de Paranavaí - PR

PR, buscou-se utilizar um modelo digital de terreno para extração dos atributos topográficos, e a carta de solos em escala semidetalhada, 1:50.000 (FASOLO et al. 1988).

\section{MATERIAIS E MÉTODOS}

Crepani et al. (2001) utiliza componentes do meio físico como relevo, clima, geologia, pedologia e vegetação para fazer inferências quanto às relações entre morfogênese e pedogênese em unidades de paisagem natural. Cada elemento possui uma relevante importância na estabilidade das unidades de paisagem, a Geologia é utilizada para entender a história da evolução geológica do ambiente onde a unidade se encontra, e as informações relativas ao grau de coesão das rochas que a compõem. A geomorfologia oferece, para a caracterização da estabilidade das unidades de paisagem natural, as informações relativas à Morfometria, que influenciam de maneira marcante os processos ecodinâmicos ocorrem nas vertentes. A Pedologia fornece informações quanto ao grau de evolução dos solos. A vegetação 'representa a defesa da unidade de paisagem contra os efeitos dos processos modificadores das formas de relevo (erosão)". Os dados climatológicos representam informações a cerca da quantidade e da duração das chuvas ao longo do ano nas unidades de paisagem (CREPANI et al. p. 13,14,15, 2001).

A equação proposta por Crepani et al. (2001), define que a vulnerabilidade de uma área é definida pela soma das vulnerabilidades dos componentes do meio físico (Equação $1)$.

$$
V=\frac{(G+R+S+V g+C)}{5}
$$

onde: $\mathrm{V}=$ Vulnerabilidade $; \mathrm{G}=$ Geologia $; \mathrm{S}=$ Solos; $\mathrm{Vg}=$ Vegetação e $\mathrm{C}=$

Clima.

O método proposto por Crepani et al. (2001) tem como objetivo a identificação de áreas vulneráveis à perda natural de solo, sendo comumente utilizado na definição de áreas suscetíveis a processos erosivos laminares. Porém, como o objetivo do trabalho é analisar as diferenças ao longo do município, os valores de suscetibilidade para os atributos vegetação, 
OLIVEIRA, J. G.; NOWATZKI, A.; SANTOS, L. J. C.

Utilização de atributos topográficos no mapeamento de suscetibilidade erosiva na área rural do município de Paranavaí - PR

geologia e clima não foram levados em consideração, visto sua baixa variação espacial no município (Figura 2).

Figura 2 - A: Geologia de Paranavaí. B:Vegetação de Paranavaí. A figura mostra a baixa variação nos atributos geologia e vegetação na escala de dados disponível para o município

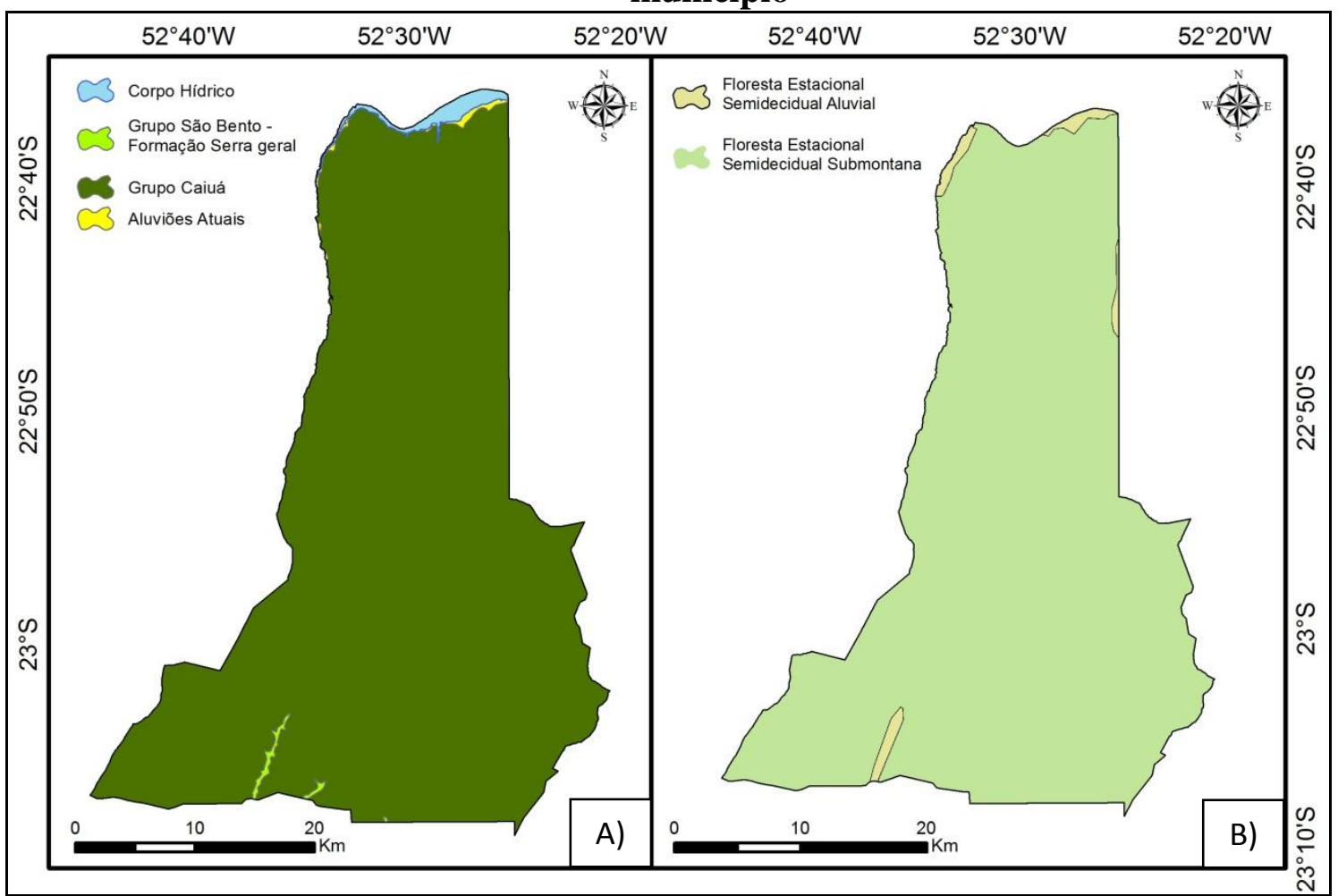

Fonte: CPRM;ITCG. Org: O autor (2017).

Deste modo, foram isolados apenas os elementos do meio físico que tem relevância direta nos processos erosivos para a área em estudo, sendo eles: Relevo e Solos. Logo, o método proposto por Crepani et al. (2001) será simplificado, de modo a principal contribuição do autor para o presente artigo ser a técnica de atribuição de pesos as classes dos atributos do meio físico.

O mapa de solos (Figura 3) utilizado neste trabalho foi elaborado por Fasolo et al. (1988). na escala 1:55.000. A elaboração de levantamentos de solos nesta escala (semidetalhados) tem-se por finalidade a obtenção de informações básicas para implantação de projetos de colonização, loteamentos rurais, estudos integrados de bacias hidrográficas, entre outros objetivos. Toda a base encontrava-se em formato analógico, foi convertida em ambiente SIG para formato digital, georreferenciada e transformada em arquivo vetorial 
OLIVEIRA, J. G.; NOWATZKI, A.; SANTOS, L. J. C.

Utilização de atributos topográficos no mapeamento de suscetibilidade erosiva na área rural do município de Paranavaí - PR

utilizando o software Arcgis 10.3. O mapa utilizava o sistema de classificação de solos anterior e foi convertida para a atual classificação (Embrapa, 2006).

Figura 3 - Mapa de solos de Paranavaí

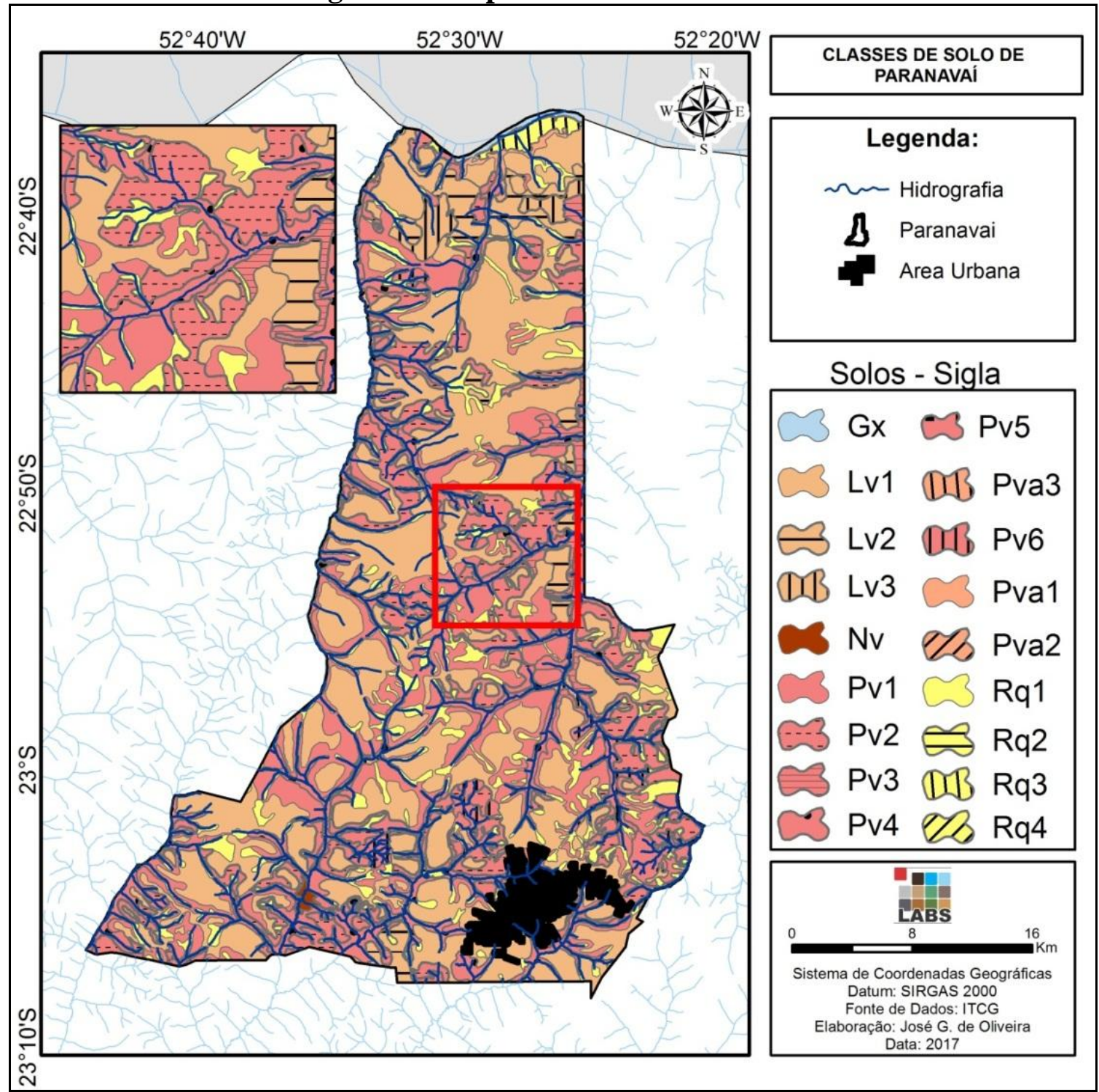

Fonte: Fasolo et al. (1988) Org. O autor (2017).

$\mathrm{Na}$ área de estudo, os solos predominantes são os Latossolos e os Argissolos, sendo que os Argissolos representam cerca de $560 \mathrm{~km}^{2}$, enquanto os Latossolos ocupam cerca de $480 \mathrm{~km}^{2}$. Os Neossolos Quartzarêrnicos, por sua vez, ocupam cerca de $130 \mathrm{~km}^{2}$; os Gleissolos, $4 \mathrm{~km}^{2}$. (Quadro 1) 
OLIVEIRA, J. G.; NOWATZKI, A.; SANTOS, L. J. C.

Utilização de atributos topográficos no mapeamento de suscetibilidade erosiva na área rural do município de

Paranavaí - PR

Quadro 1 - Classes de solo de Paranavaí

\begin{tabular}{|c|c|c|c|c|c|}
\hline $\begin{array}{c}\text { SIGLA } \\
\text { ORIGINAL }\end{array}$ & $\begin{array}{c}\text { DESCRIÇÃO } \\
\text { ORIGINAL }\end{array}$ & SBCS (2008) & $\begin{array}{c}\text { SIGLA } \\
\text { (SBCS, } \\
\text { 2008) }\end{array}$ & Sigla Usada & Área $\left(\mathrm{Km}^{2}\right)$ \\
\hline $\mathrm{Le}_{1}$ & $\begin{array}{c}\text { LATOSSOLO } \\
\text { VERMELHO } \\
\text { ESCURO: A moderado } \\
\text { textura areia ou areia } \\
\text { franca/franco-arenosa }\end{array}$ & $\begin{array}{l}\text { Latossolo } \\
\text { Vermelho }\end{array}$ & LV & $\mathrm{LV}_{1}$ & 422,5993 \\
\hline $\mathrm{Le}_{2}$ & $\begin{array}{c}\text { LATOSSOLO } \\
\text { VERMELHO } \\
\text { ESCURO: A moderado } \\
\text { textura areia franca ou } \\
\text { franco-arenosa/franco- } \\
\text { argilo-arenosa }\end{array}$ & $\begin{array}{l}\text { Latossolo } \\
\text { Vermelho }\end{array}$ & LV & $\mathrm{LV}_{2}$ & 42,91914 \\
\hline $\mathrm{Le}_{3}$ & $\begin{array}{c}\text { LATOSSOLO } \\
\text { VERMELHO } \\
\text { ESCURO: A moderado } \\
\text { textura franco-argilo- } \\
\text { arenosa ou argila } \\
\text { arenosa/argila arenosa } \\
\text { ou argila }\end{array}$ & $\begin{array}{l}\text { Latossolo } \\
\text { Vermelho }\end{array}$ & LV & $\mathrm{LV}_{3}$ & 13,17056 \\
\hline $\operatorname{Tr}$ & $\begin{array}{c}\text { TERRA ROXA } \\
\text { ESTRUTURADA: A } \\
\text { moderado textura } \\
\text { argilosa ou muito } \\
\text { argilosa }\end{array}$ & Nitossolo Vermelho & NV & NV & 1,847598 \\
\hline $\mathrm{Pe}_{1}$ & $\begin{array}{c}\text { PODZOLICO } \\
\text { VERMELHO- } \\
\text { ESCURO: Latossolico } \\
\text { A moderado textura } \\
\text { areia ou areia } \\
\text { franca/franco-arenosa } \\
\text { ou franco-argilo- } \\
\text { arenosa }\end{array}$ & $\begin{array}{l}\text { Argissolo } \\
\text { Vermelho }\end{array}$ & PV & $\mathrm{PV}_{1}$ & 164,1943 \\
\hline $\mathrm{Pe}_{2}$ & $\begin{array}{c}\text { PODZOLICO } \\
\text { VERMELHO- } \\
\text { ESCURO: A moderado } \\
\text { textura areia ou areia } \\
\text { franca/franco-arenosa } \\
\text { ou franco-argilo- } \\
\text { arenosa }\end{array}$ & $\begin{array}{l}\text { Argissolo } \\
\text { Vermelho }\end{array}$ & PV & $\mathrm{PV}_{2}$ & 193,8368 \\
\hline $\mathrm{Pe}_{3}$ & $\begin{array}{c}\text { PODZOLICO } \\
\text { VERMELHO- } \\
\text { ESCURO: A moderado } \\
\text { textura franco-arenosa } \\
\text { ou franco-argilo- } \\
\text { arenosa }\end{array}$ & $\begin{array}{l}\text { Argissolo } \\
\text { Vermelho }\end{array}$ & PV & $\mathrm{PV}_{3}$ & 19,13493 \\
\hline $\mathrm{Pe}_{4}$ & PODZOLICO & Argissolo & PV & $\mathrm{PV}_{4}$ & 146,8234 \\
\hline
\end{tabular}


OLIVEIRA, J. G.; NOWATZKI, A.; SANTOS, L. J. C.

Utilização de atributos topográficos no mapeamento de suscetibilidade erosiva na área rural do município de Paranavaí - PR

\begin{tabular}{|c|c|c|c|c|c|}
\hline $\begin{array}{c}\text { SIGLA } \\
\text { ORIGINAL }\end{array}$ & $\begin{array}{l}\text { DESCRIÇÃO } \\
\text { ORIGINAL }\end{array}$ & SBCS (2008) & $\begin{array}{c}\text { SIGLA } \\
\text { (SBCS, } \\
\text { 2008) }\end{array}$ & Sigla Usada & Área $\left(\mathrm{Km}^{2}\right)$ \\
\hline & $\begin{array}{c}\text { VERMELHO- } \\
\text { ESCURO: abrupto A } \\
\text { moderado textura areia } \\
\text { ou areia franca/franco } \\
\text { arenosa ou franco- } \\
\text { argilo-arenosa }\end{array}$ & Vermelho & & & \\
\hline $\mathrm{Pe}_{5}$ & $\begin{array}{c}\text { PODZOLICO } \\
\text { VERMELHO- } \\
\text { ESCURO: abrupto A } \\
\text { moderado textura areia } \\
\text { ou areia franco- } \\
\text { arenosa/franco-argilo- } \\
\text { arenosa ou argila } \\
\text { arenosa } \\
\end{array}$ & $\begin{array}{l}\text { Argissolo } \\
\text { Vermelho }\end{array}$ & PV & $\mathrm{PV}_{5}$ & 2,02735 \\
\hline $\mathrm{Pe}_{6}$ & $\begin{array}{c}\text { PODZOLICO } \\
\text { VERMELHO- } \\
\text { ESCURO: abrupto A } \\
\text { moderado textura areia } \\
\text { ou areia franca/franco- } \\
\text { argilo-arenosa }\end{array}$ & $\begin{array}{l}\text { Argissolo } \\
\text { Vermelho }\end{array}$ & PV & $\mathrm{PV}_{6}$ & 28,42957 \\
\hline$P v_{1}$ & $\begin{array}{c}\text { PODZOLICO } \\
\text { VERMELHO- } \\
\text { AMARELO: A } \\
\text { moderado textura areia } \\
\text { ou areia franca/franco- } \\
\text { argilo-arenosa }\end{array}$ & $\begin{array}{c}\text { Argissolo } \\
\text { Vermelho-Amarelo }\end{array}$ & PVA & $\mathrm{PVA}_{1}$ & 3,805119 \\
\hline $\mathrm{Pv}_{2}$ & $\begin{array}{c}\text { PODZOLICO } \\
\text { VERMELHO- } \\
\text { AMARELO: abrupto A } \\
\text { moderado textura areia } \\
\text { ou areia franca/franco- } \\
\text { arenosa ou franco- } \\
\text { argilo-arenosa }\end{array}$ & $\begin{array}{c}\text { Argissolo } \\
\text { Vermelho-Amarelo }\end{array}$ & PVA & $\mathrm{PVA}_{2}$ & 0,538344 \\
\hline $\mathrm{Pv}_{3}$ & $\begin{array}{c}\text { PODZOLICO } \\
\text { VERMELHO- } \\
\text { AMARELO: abrupto A } \\
\text { moderado textura areia } \\
\text { ou areia franca/franco- } \\
\text { arenosa ou franco- } \\
\text { argilo-arenosa }\end{array}$ & $\begin{array}{c}\text { Argissolo } \\
\text { Vermelho-Amarelo }\end{array}$ & PVA & $\mathrm{PVA}_{3}$ & 1,890566 \\
\hline $\mathrm{Aq}_{1}$ & $\begin{array}{c}\text { AREIAS } \\
\text { QUARTZOSAS } \\
\text { VERMELHO- } \\
\text { AMARELO: A } \\
\text { moderado textura areia } \\
\text { ou areia franca } \\
\end{array}$ & $\begin{array}{c}\text { Neossolo } \\
\text { Quartzarênico }\end{array}$ & RQ & $\mathrm{RQ}_{1}$ & 116,0638 \\
\hline $\mathrm{Aq}_{2}$ & $\begin{array}{c}\text { AREIAS } \\
\text { QUARTZOSAS: A } \\
\text { moderado textura areia }\end{array}$ & $\begin{array}{c}\text { Neossolo } \\
\text { Quartzarênico }\end{array}$ & RQ & $\mathrm{RQ}_{2}$ & 0,742284 \\
\hline
\end{tabular}


OLIVEIRA, J. G.; NOWATZKI, A.; SANTOS, L. J. C.

Utilização de atributos topográficos no mapeamento de suscetibilidade erosiva na área rural do município de Paranavaí - PR

\begin{tabular}{|c|c|c|c|c|c|}
\hline $\begin{array}{c}\text { SIGLA } \\
\text { ORIGINAL }\end{array}$ & $\begin{array}{c}\text { DESCRIÇÃO } \\
\text { ORIGINAL }\end{array}$ & SBCS (2008) & $\begin{array}{c}\text { SIGLA } \\
\text { (SBCS, } \\
\mathbf{2 0 0 8 )}\end{array}$ & Sigla Usada & Área $\left(\mathrm{Km}^{2}\right)$ \\
\hline $\mathrm{Aq}_{3}$ & $\begin{array}{c}\text { AREIAS } \\
\text { QUARTZOSAS } \\
\text { HIDROMÓRFICAS: } \\
\text { A moderado textura } \\
\text { areia ou areia franca }\end{array}$ & $\begin{array}{c}\text { Neossolo } \\
\text { Quartzarênico }\end{array}$ & RQ & $\mathrm{RQ}_{3}$ & 11,24288 \\
\hline $\mathrm{Aq}_{4}$ & $\begin{array}{c}\text { AREIAS } \\
\text { QUARTZOSAS } \\
\text { VERMELHO- } \\
\text { AMARELAS } \\
\text { podzolizadas A } \\
\text { moderado textura areia } \\
\text { ou areia franca }\end{array}$ & $\begin{array}{c}\text { Neossolo } \\
\text { Quartzarênico }\end{array}$ & RQ & $\mathrm{RQ}_{4}$ & 0,73974 \\
\hline $\mathrm{Hgp}_{1}$ & $\begin{array}{c}\text { GLEI POUCO } \\
\text { HÚMICO: textura } \\
\text { franco-argilosa ou } \\
\text { argila. }\end{array}$ & Gleissolo Háplico & GX & GX & 3,367487 \\
\hline
\end{tabular}

Fonte: Fasolo et al (1988). Org: O autor (2017).

Para a variável geomorfologia, foram analisados atributos topográficos (Perfil de curvatura e declividade), sendo que para e elaboração desses índices, foi gerado um modelo digital do terreno (MDT). O MDT é uma representação com valores numéricos que indicam a altimetria local através de uma matriz regular (MOORE et al. 1993; TOMLIM, 1983; WEISS, 2001; McKENZIE e RYAN, 1999; McBRATNEY et al. 2003).

Para a geração do MDT, foram utilizadas curvas de nível, com equidistância de 20m, pontos cotados e hidrografia, obtidos do Instituto de Terras Cartografia e Geociências do Paraná (ITCG) e da agência Águas Paraná na escala 1:50.000. O MDT foi gerado no software Arcgis 10.3, utilizando o algoritmo ANUDEM, o algoritmo foi selecionado por ser hidrologicamente consistente, essa ferramenta parte do método de interpolação denominado Topogrid proposto por Hutchinson (1989) a qual se baseia em um algoritmo que remove reentrâncias, falsas depressões, possibilitando que o modelo possua áreas com livre escoamento superficial (SILVA et al., 2017). A definição de célula do MDT se deu após a aplicação do cálculo proposto por Hengl (2006), sendo definido o tamanho de $15 \mathrm{~m}$.

A declividade ou clinografia $(\alpha)$ diz respeito ao grau do terreno em relação ao plano. O agrupamento dos valores em categorias se deu por meio de adaptações nas classes sugeridas em Crepani et al. (2001), com base nas características locais do relevo. Para a área de estudo foram divididas quatro classes, de 0 a $2 \%$, de 2 a $6 \%$, de 6 a $20 \%$ e maiores que 20\%. O perfil de curvatura se refere à forma de vertente, podendo ser convexa, côncava ou 
retilínea (SIRTOLI et al. 2008). Ambas as informações se encontram ilustradas na figura 4.

A influência do perfil de curvatura está relacionada, principalmente, ao controle que as formas do relevo exercem na distribuição de águas e materiais solúveis ao longo das vertentes (CHAGAS, 2006). As áreas côncavas se localizam, principalmente, nos fundos de vale, enquanto as porções convexas se localizam em topos e em partes de maior declividade. Nas porções de vertente côncavas, existe uma tendência maior a concentração da água em fluxos, aumentando as chances de erosão nesses locais.

\section{Figura 4 - Declividade e Perfil de Curvatura de Paranavaí}

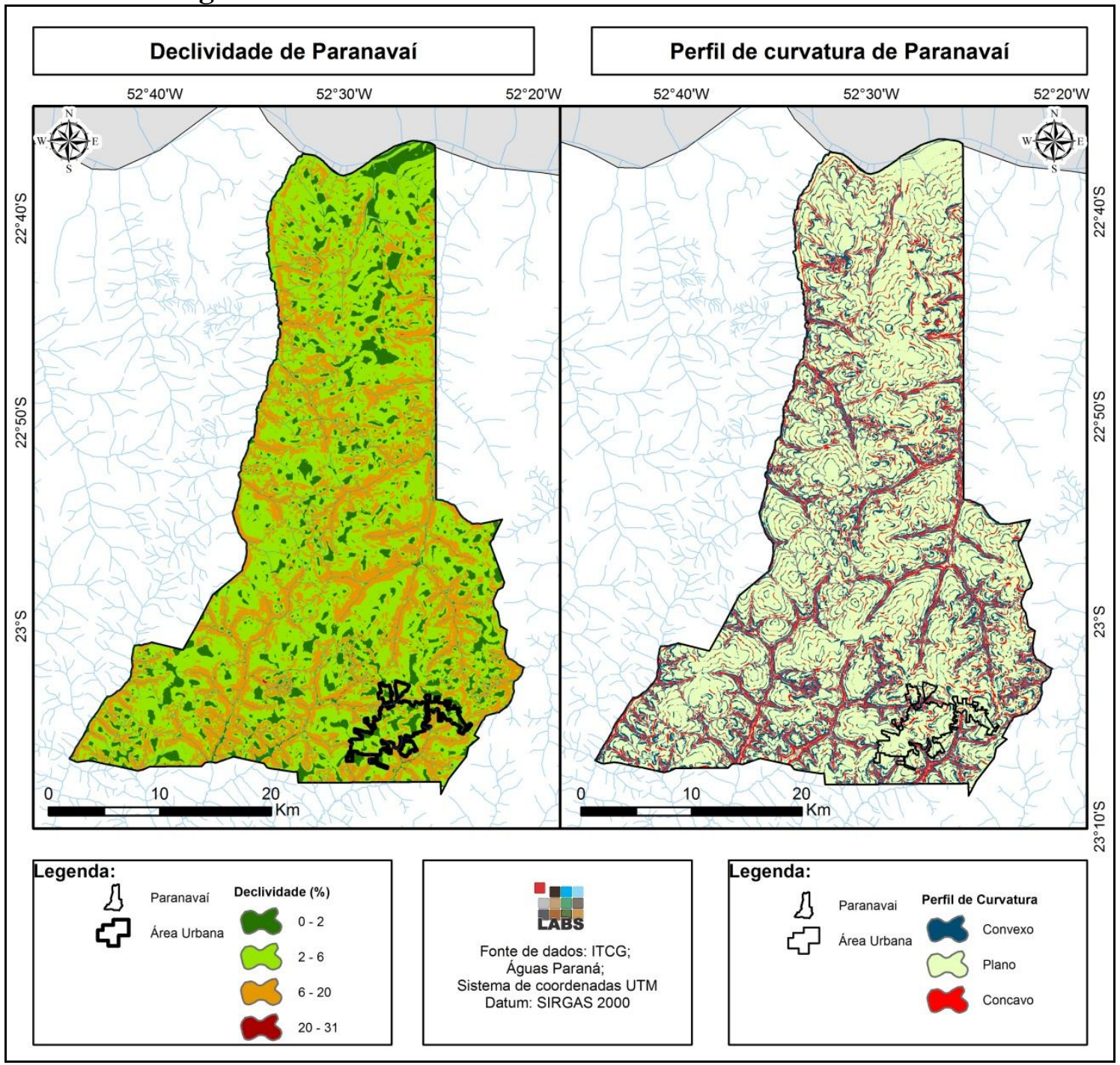

Fonte: ITCG; Aguas Paraná. Org: O autor (2017).

Após a definição e organização das bases cartográficas utilizadas, bem como a definição dos pesos para os atributos (Quadros 1,2 e 3), a soma matricial dos mapas foi efetivada. A soma foi realizada em ambiente SIG, através da calculadora matricial "raster 
OLIVEIRA, J. G.; NOWATZKI, A.; SANTOS, L. J. C.

Utilização de atributos topográficos no mapeamento de suscetibilidade erosiva na área rural do município de Paranavaí - PR

calculator"' do software Arc Gis, modulo Arc Map 10.3. A relação dos mapas foi feita por meio da fórmula (Equação 2) a seguir e os pesos atribuídos foram aplicados de acordo com a fragilidade de cada classe nos atributos (Tabela 1):

Os resultados foram discretizados em 5 classes (Tabela 1), partindo dos ambientes menos suscetíveis para os mais suscetíveis (CREPANI et al. 2001). Os intervalos foram adaptados dos originais propostos para se adequar as características naturais da área em estudo.

Quadro 1 - Discretização do Atributo Solo

\begin{tabular}{|c|c|}
\hline SUSCETIBILIDADE & SOLOS \\
\hline BAIXA & GX; NV. \\
\hline MÉDIA & LV1;LV2;LV3. \\
\hline MÉDIA-ALTA & PV1;PV2;PV3;PV4;PV5; \\
& PV6;PVA1;PVA2;PVA3. \\
\hline ALTA & RQ1;RQ2;RQ3;RQ4. \\
\hline
\end{tabular}

Adaptado de Crepani et al. (2001).

\section{Quadro 2 - Discretização do Atributo Declividade}

\begin{tabular}{|c|c|}
\hline SUSCETIBILIDADE & $\begin{array}{c}\text { DECLIVIDADE } \\
(\boldsymbol{\%})\end{array}$ \\
\hline MUITO BAIXA & $<2$ \\
\hline BAIXA & $2-6$ \\
\hline MÉDIA & $6-20$ \\
\hline ALTA & $20-50$ \\
\hline
\end{tabular}

Adaptado de Crepani et al. (2001).

\section{Quadro 3 - Discretização do Atributo Perfil de Curvatura}

\begin{tabular}{|c|c|}
\hline SUSCETIBILIDADE & $\begin{array}{c}\text { PERFIL DE } \\
\text { CURVATURA }\end{array}$ \\
\hline BAIXA & CONVEXO \\
\hline MÉDIA & RETILINEO \\
\hline ALTA & CONCAVO \\
\hline
\end{tabular}

Adaptado de Crepani et al. (2001).

$$
S=[(S O L O * 5)+(D E C L I V I D A D E * 4)+(P E R F C U R V)] / 10
$$

onde $\mathrm{S}=$ Suscetibilidade . 
OLIVEIRA, J. G.; NOWATZKI, A.; SANTOS, L. J. C.

Utilização de atributos topográficos no mapeamento de suscetibilidade erosiva na área rural do município de Paranavaí - PR

Tabela 1 - Intervalos de suscetibilidade

\begin{tabular}{c|c|c}
\hline $\begin{array}{c}\text { INTERVALOS (CREPANI } \\
\text { et al. 2001) }\end{array}$ & $\begin{array}{c}\text { INTERVALOS } \\
\text { (PROPOSTOS) }\end{array}$ & $\begin{array}{c}\text { CLASSES DE } \\
\text { SUSCETIBILIDADE }\end{array}$ \\
\hline $1-1,3$ & $1-1,3$ & MUITO BAIXA \\
\hline $1,4-1,7$ & $1,3-1,8$ & BAIXA \\
\hline $1,8-2,2$ & $1,8-2,1$ & MÉDIA \\
\hline $2,3-2,6$ & $2,1-2,4$ & ALTA \\
\hline $2,7-3$ & $2,4-3$ & MUITO ALTA \\
\hline \multicolumn{2}{|c}{ Fonte: Crepani et al., 2001.}
\end{tabular}

Para validação dos resultados encontrados no mapa de suscetibilidade, foi utilizado o mapa de feições erosivas produzido por Mangueira (2014). Foram identificadas 918 feições erosivas na região do noroeste do Estado, sendo 46 localizadas no município de Paranavaí (Figura 2).

Figura 2 - Mapa com as feições erosivas do município de Paranavaí

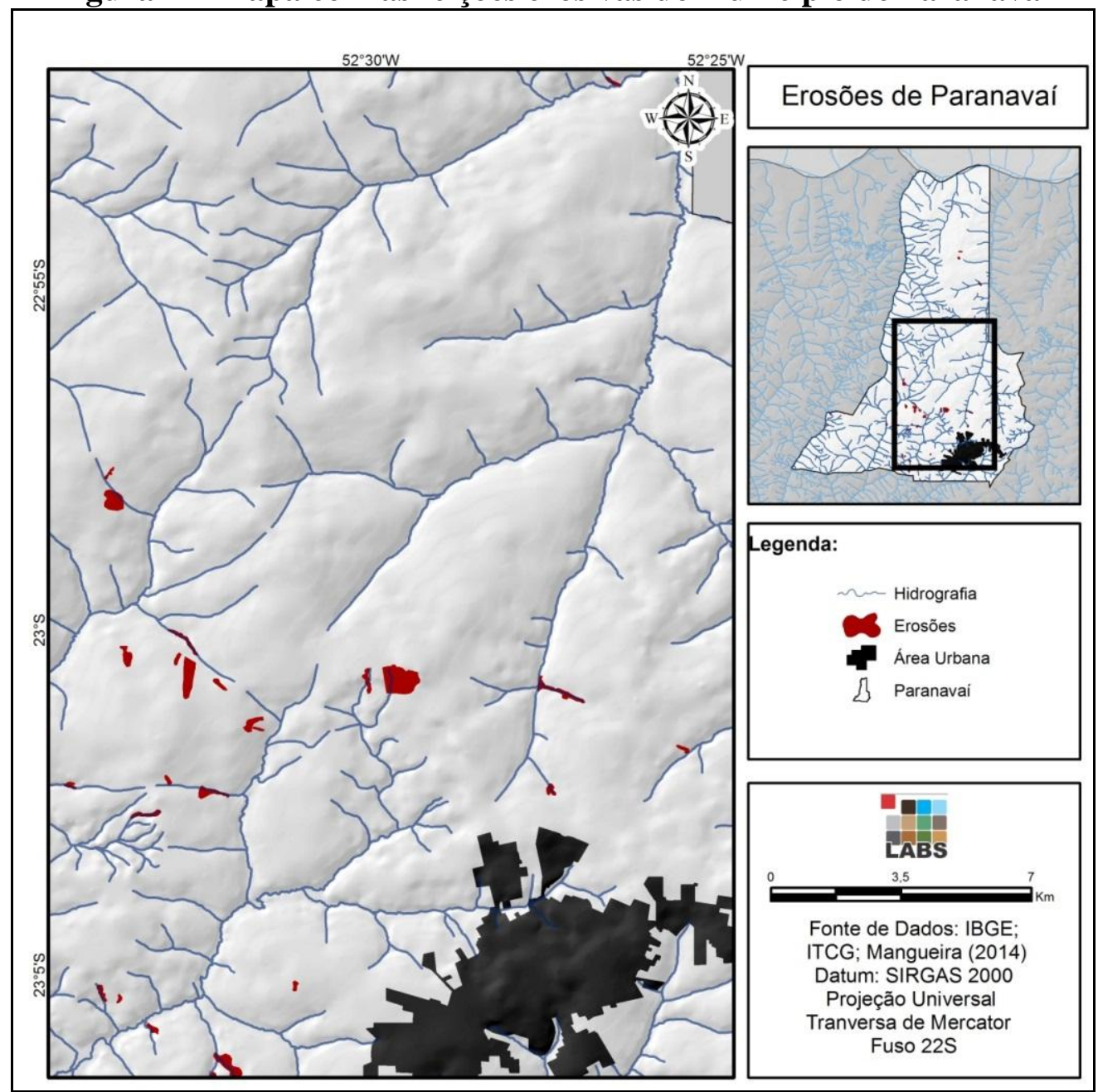

Fonte: Mangueira (2014). Org. O autor (2017). 
OLIVEIRA, J. G.; NOWATZKI, A.; SANTOS, L. J. C.

Utilização de atributos topográficos no mapeamento de suscetibilidade erosiva na área rural do município de

\section{RESULTADOS}

Paranavaí - PR

A partir do cruzamento matricial dos atributos anteriormente citados, obteve-se o mapa de áreas suscetíveis a processos erosivos para o município de Paranavaí (Figura 5 e tabela 2).

\section{Figura 5 - Suscetibilidade à erosão em Paranavaí}

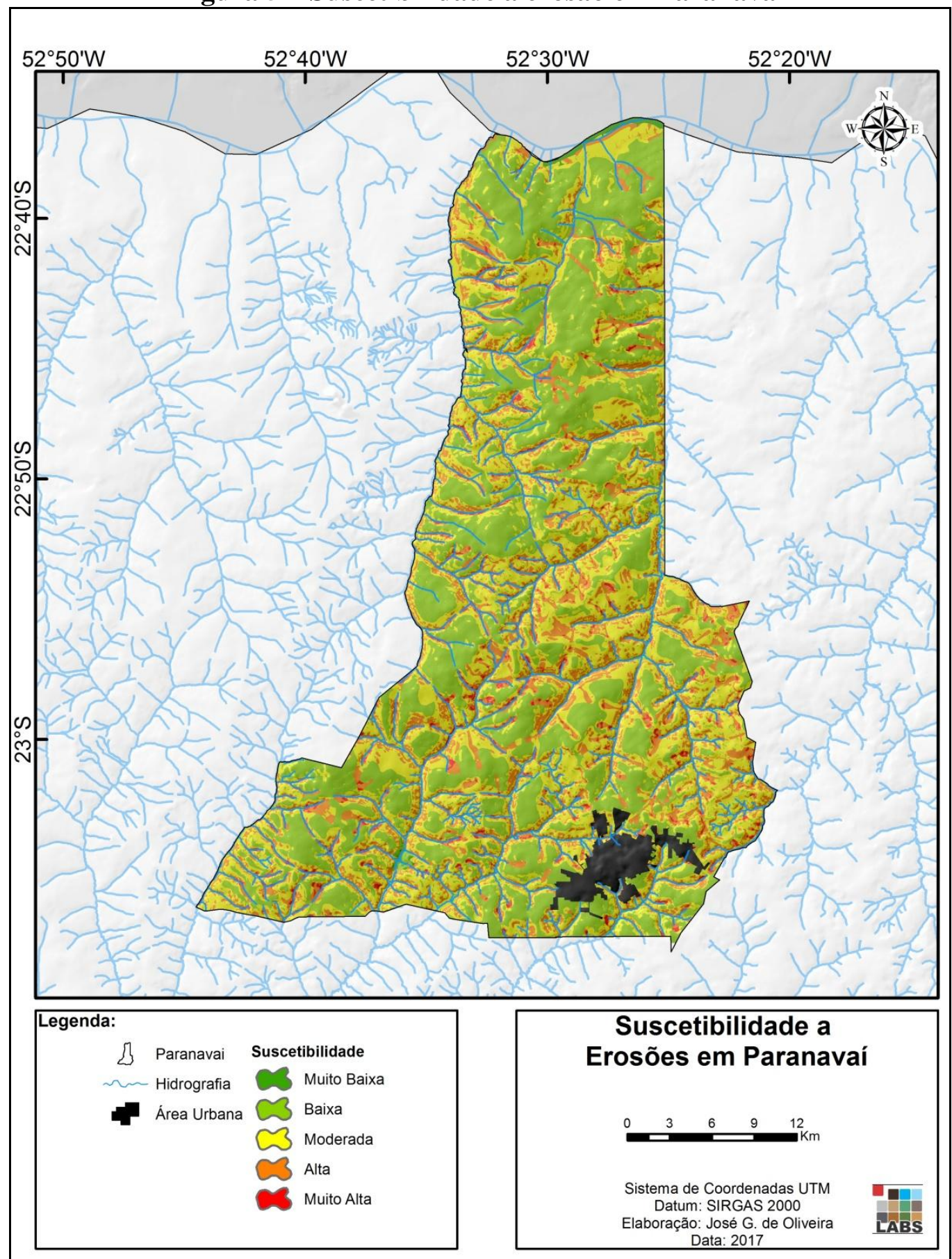

Org: O autor (2017). 
OLIVEIRA, J. G.; NOWATZKI, A.; SANTOS, L. J. C.

Utilização de atributos topográficos no mapeamento de suscetibilidade erosiva na área rural do município de Paranavaí - PR

Tabela 2 - Classes de suscetibilidade à erosão

\begin{tabular}{c|c|c}
\hline $\begin{array}{c}\text { CLASSES DE } \\
\text { SUSCETIBILIDADE }\end{array}$ & ÁREA $\left(\mathbf{K M}^{\mathbf{2}}\right)$ & ÁREA $(\%)$ \\
\hline MUITO BAIXA & 4,22 & 0,4 \\
\hline BAIXA & 422,68 & 36 \\
\hline MODERADA & 464,93 & 39,6 \\
\hline ALTA & 257,70 & 22 \\
\hline
\end{tabular}

Fonte: o autor (2017).

- $\quad$ Suscetibilidade Muito baixa: esse grupo engloba os Nitossolos e a planície do rio Paranapanema, a declividade é baixa e os solos bem drenados no caso dos Nitossolos ou constantemente alagados dos Gleissolos, logo, é a área com menor suscetibilidade à ocorrência de erosões. Isso ocorre quando se compara as erosões com a unidade em questão, sendo que nenhuma erosão das mapeadas por Mangueira (2014) se encontra nesse grupo.

- $\quad$ Suscetibilidade Baixa: dentro desse grupo, estão, principalmente, os topos e as áreas com declividade abaixo de $6 \%$ e quanto aos solos há maior ocorrência dos latossolos. Cerca de $10 \%$ da área das erosões se encontra nessa unidade. Sendo assim, as erosões dentro dessa classe podem ser entendidas como em processo avançado de evolução (erosão remontante), pois se encontram próximas aos seus divisores topográficos.

- Suscetibilidade Moderada: esse grupo se localiza nos terços médios das vertentes, principalmente em áreas de Latossolos e Argissolos. Geralmente as declividades encontradas estão acima de $6 \%$ e as vertentes são retilíneas. Esse grupo tem a maior concentração de feições erosivas, abrangendo cerca de 54\% dessas erosões.

- $\quad$ Suscetibilidade Alta: os solos dessa classe são principalmente os Argissolos e os Neossolos Quartzarenicos. Quanto à declividade, é maior que $20 \%$ nas porções com Argissolos e acima de 6\% nas porções com Neossolos. Cerca de 33\% da área das erosões rurais de Paranavaí estão nessa unidade.

- Suscetibilidade Muito Alta: nessa área, encontram-se os Neossolos Quartzarenicos, a declividade é maior que $20 \%$ e as vertentes predominantemente côncavas. Nesse grupo, estão 3\% das erosões mapeadas. A área pequena dessa classe acontece devido aos Neossolos terem sua ocorrência em fundos de vale ou cabeceiras de drenagem, sendo que 
OLIVEIRA, J. G.; NOWATZKI, A.; SANTOS, L. J. C.

Utilização de atributos topográficos no mapeamento de suscetibilidade erosiva na área rural do município de
Paranavaí - PR nessas porções a declividade é majoritariamente baixa, portanto, as características naturais que levam a máxima suscetibilidade à erosão natural no município são de rara ocorrência.

Os resultados gerados demonstram que a maior parte do município se enquadra na classe de suscetibilidade moderada, sendo que nesse grau de suscetibilidade podem ocorrer resultados expressivos em perda de solo conforme ressalta Borges et al. (2009). A aplicação do método proposto por Crepani et al. (2001) é comumente feita para produção de sedimentos

\section{CONCLUSÕES}

Como o objetivo do trabalho era avaliar as relações entre solo/relevo e as feições erosivas identificadas por Mangueira (2014) a técnica de integração de variáveis proposta por Crepani et al. (2001) pode ser utilizada, visto que o autor sistematiza a distribuição de pesos a classes de suscetibilidade dos determinados elementos do meio físico.

Os resultados gerados no presente trabalho atingiram os objetivos propostos e se mostraram condizentes com a literatura. As classes de suscetibilidade a erosão Alta e Muito alta, somadas, representam $24 \%$ do município, sendo que, nelas, concentra-se $26 \%$ das erosões mapeadas por Mangueira (2014). Nessas classes, os tipos de solos, em conjunto com as características topográficas como declividade e perfil de curvatura, tornam as áreas naturalmente mais propícias à ocorrência dos processos erosivos lineares.

A classe de moderada suscetibilidade a erosão representam cerca de $40 \%$ do município e ocorre uma concentração de $54 \%$ das feições erosivas. Isso mostra que para essa região a ocorrência das erosões está relacionada também as atividades antrópicas, como agricultura e pastagem, conforme aponta Mangueira (2014).

Por fim, destaca-se a aplicabilidade do método proposto por Crepani et al. (2001) para avaliações de cunho ambiental, bem como que adaptações na metodologia se mostraram coerentes na análise de diferentes fenômenos espaciais. Cabe ressaltar que a utilização de um mapa de solos em escala de semidetalhe possibilitou uma maior confiabilidade nos resultados gerados.

O método proposto por Crepani et al. (2001) é comumente utilizado para estimar a produção de sedimentos, logo, sua utilização é feita para processos erosivos de cunho laminar, as variáveis propostas pelo autor, dependem de bases cartográficas em escalas de 
OLIVEIRA, J. G.; NOWATZKI, A.; SANTOS, L. J. C.

Utilização de atributos topográficos no mapeamento de suscetibilidade erosiva na área rural do município de Paranavaí - PR

detalhe, em escalas como a do presente trabalho, as variações espaciais no aspecto geológico e fitogeográfico são pouco expressivas tornando a sua utilização desnecessária.

\section{REFERÊNCIAS}

BORGES, R. O.; SILVA, R. A. A.; CAMPAGNOLI, F.; CASTRO, S. S. Mapeamento da evolução da produção de sedimentos no setor sul da Alta Bacia do Rio Araguaia. In: Simpósio Nacional de Controle de Erosão, 8. São Paulo, 2009. Anais do VIII Simpósio Nacional de Controle de Erosão, 2009.

CHAGAS, C. S. Mapeamento digital de solos por correlação ambiental e redes neurais em uma bacia hidrográfica no domínio de mar de morros. Viçosa, 2006. 223p.

(Doutorado -Universidade Federal de Viçosa $\square$ UFV.

CREPANI, E.; MEDEIROS, J.S de. FILHO, P.H; FLORENZANO, T.G; DUARTE, V.; BARBOSA, C.C.F. Sensoriamento remoto e geoprocessamento aplicados ao zoneamento ecológico-econômico e ao ordenamento territorial. São José dos Campos: INPE, 2001.

EMBRAPA (Empresa Brasileira de Pesquisa Agropecuária). Sistema Brasileiro de Classificação de Solos. Centro Nacional de Pesquisa de Solos. 2. Ed. Rio de Janeiro: Embrapa Solos, 2006.

FASOLO, P. J.; CARDOSO, A.; CARVALHO, A. D.; HOCHMÜLLER, D.; RAUEN, M. D. J.; \& PÖTTER, R. (1988). Erosão: inventário de áreas críticas no Noroeste do Paraná. Curitiba, Instituto Agronômico do Paraná,1988.

FAO (Food and Agriculture Organization). The State of Food Insecurity in the World 2015. Food and Agriculture Organization Publications, Rome. 2015

FERNANDES, L. A.; COUTO, E. V.; SANTOS, L. J. C. Três Morrinhos, Terra Rica, PR. Arenitos silicificados de dunas do Deserto Caiuá testemunham nível de superfície de aplainamento K-T. Sítios Geológicos e Paleontológicos do Brasil - SIGEP, 2012.

HENGL, T. Finding the right pixel size. Computers \& Geosciences, v. 32, n. 9, p. 1283 1298, 2006.

HUTCHINSON, M. F. Calculation of hydrologically sound digital elevation models. Paper presented at Third International Symposium on Spatial Data Handling at Sydney. Australia, 1989.

IAPAR (Instituto Agronômico do Estado do Paraná) . Cartas climáticas do Estado do Paraná. 1994. Londrina, IAPAR, 1994. 49 p. ilust. (IAPAR, Documento, 18).

LEPSCH, I.F. Formação e conservação dos solos. Oficina de textos, 2010. 
MANGUEIRA, C.G. Processos erosivos no noroeste do paraná: mapeamento e análise da distribuição. 2014. 35 f. TCC (Graduação) - Curso de Geografia, Universidade Federal do Paraná, Curitiba, 2014.

MANGUEIRA, C.G. Proposta De Classificação Do Nível De Criticidade Dos Processos Erosivos Da Região Noroeste Do Paraná. 2017. 91 f. Dissertação (Mestrado) - Curso de Geografia, Universidade Federal do Paraná, Curitiba, 2017.

MESQUITA, C; DE ASSIS, A.Q.S; DE SOUZA, R.M. Vulnerabilidade natural à perda de solos da bacia hidrográfica do Rio Sagrado-Morretes/PR. Revista de Geografia (Recife), v. 27, n. 2, p. 251-264, 2010.

McBRATNEY, A. B.; MENDONÇA-SANTOS, M. L.; MINASNY, B. On digital soil mapping. Geoderma, v. 117, p. 3-52, 2003.

McKENZIE, N.J., RYAN, P.J., 1999. Spatial prediction of soil properties using environmental correlation. Geoderma 89, 67-94.

MOORE, I. D.; GESSLER, P. E.; NIELSEN, G. A.; PETERSON, G. A. Soil attribute prediction using terrain analysis. Soil Science Society American Journal. v. 57, p. 443-452, 1993.

RIBEIRO, F.L.; CAMPOS, S. Vulnerabilidade à erosão do solo da região do Alto Rio Pardo, Pardinho, SP. Revista brasileira de engenharia agrícola e ambiental, p. 628-636, 2007.

SANTOS, C.A; SOBREIRA, F.G. Análise morfométrica como subsídio ao zoneamento territorial: o caso das bacias do Córrego Carioca, Córrego do Bação e Ribeirão Carioca na região do Alto Rio das Velhas-MG. Rev. Esc. Minas [online]. 2008.

SANTOS, L.J.C. et al. Mapeamento geomorfológico do Estado do Paraná. Revista Brasileira de Geomorfologia, ano, v. 7, p. 3-12, 2006.

SILVA, J. M. F.; OKA-FIORI, C.; SILVEIRA, C. T. Índice de Diversidade de Formas de Relevo do Setor Norte da Apa da Serra da Esperança (PR) com Emprego de Técnica de Classificação Geomorfométrica. Revista do Departamento de Geografia USP, Volume Especial - Eixo 6, p.112-123, 2017

SIRTOLI, A. E., SILVEIRA, C. T. D., MANTOVANI, L. E., Anjos SIRTOLI, A. R. D., \& OKA-FIORI, C. (2008). Atributos do relevo derivados de modelo digital de elevação e suas relações com solos. Scientia agraria, 9(3).

SPÖRL, C ; ROSS, J.L.S. Análise comparativa da fragilidade ambiental com aplicação de três modelos. GEOUSP: Espaço e Tempo (Online), n. 15, p. 39-49, 2006.

SUCEAM - Superintendência do Controle da Erosão e Saneamento Ambiental.

Caracterização do meio físico: subsídios para o planejamento urbano e periurbano.

Curitiba, 1994. 23p. 
TOMLIN, C. D. A Map Algebra. In Proceedings of Harvard Computer Graphics Conference, at Cambridge, Mass, 1983.

WEISS, A. Topographic Position and Landforms Analysis. Poster presentation, ESRI User Conference, San Diego, CA, 2001.

WESTPHALEN, L. A. Avaliação e hierarquização da erodibilidade dos solos do noroeste do estado do Paraná. 2009.

WESTPHALEN, L.A. Avaliação e Hierarquização da Erodibilidade dos Solos do Noroeste do Estado do Paraná: subsídios ao planejamento ambiental. Dissertação (Mestrado em Geografia Paraná.). 90f. Universidade Federal do Paraná - UFPR, Curitiba, 2008 .

WROBLEWSKI, C. A.; PAULA, E. V.. Confecção da Carta de Suscetibilidade Geopedológica da Bacia do Rio Tagaçaba (Guaraqueçaba/PR). Revista Equador, v. 4, p. 686-693, 2015.

\section{Autores}

José Guilherme de Oliveira - Possui Graduação em Geografia pela Universidade Federal do Paraná (UFPR). Atualmente cursa Mestrado pelo Programa de Pós-Graduação em Geografia da Universidade Federal do Paraná (UFPR).

Alexei Nowatzki - Possui Graduação e Mestrado em Geografia pela Universidade Federal do Paraná (UFPR). Atualmente cursa Doutorado pelo Programa de Pós-Graduação em Geografia da Universidade Federal do Paraná (UFPR).

Leonardo José Cordeiro Santos - Possui Graduação em Geografia pela Universidade do Estado do Rio de Janeiro (UERJ), Mestrado e Doutorado em Geografia (Geografia Física) pela Universidade de São Paulo (USP). Atualmente é Professor do Programa de PósGraduação em Geografia da Universidade Federal do Paraná (UFPR).

Artigo recebido em: 30 de agosto de 2017.

Artigo aceito em: 05 de setembro de 2017. 